\title{
PNLD e a Educação Física: uma Análise Comparativa Entre os Componentes Curriculares no Ensino Fundamental ${ }^{1}$
}

\section{PNLD and Physical Education: a Comparative Analysis among the Curricular Components in Elementary School}

\author{
Igor Araujo da Silva*a; Carlos Felipe Cunha Paula ; Isabella Perrotta Lemos Fernandes ${ }^{\text {a }}$, Natalia Cristine Ramos de \\ Oliveira ${ }^{a}$; Francis Natally de Almeida Anacleto ${ }^{\mathrm{a}}$
}

${ }^{a}$ Universidade Federal Rural do Rio de Janeiro, Departamento de Educação Física e Desportos, Curso de Licenciatura em Educação Física. RJ, Brasil.

*E-mail: igor.araujos@hotmail.com

\begin{abstract}
Resumo
Os livros que possuem caráter pedagógico são intitulados de livros didáticos e surgem como uma forma de apresentar e organizar os conteúdos que serão abordados no processo de ensino e aprendizagem. Esses livros possuem os conteúdos, exercícios, ilustrações, exemplificações, isto é, múltiplas aplicabilidades pedagógicas que servirão de guia para o professor. O presente artigo tem como objetivo contextualizar a proposta do PNLD em diferentes componentes curriculares no Ensino Fundamental e comparar o componente curricular Educação Física em relação aos outros. Metodologicamente se apresenta como uma revisão bibliografica, cujo principal objeto de análise nessa revisão é a literatura produzida acerca da temática. A pesquisa foi estruturada a partir da leitura de artigos e documentos que apresentam como tema principal o PNLD. A busca destes artigos foi realizada nas bases de dados Google Acadêmico e Scielo. Destes, foram selecionados 29 artigos, que foram lidos e analisados. Para a seleção dos artigos apontados neste ensaio, o critério de inclusão considerou: a) objetivos, b) métodos; e c) considerações finais ou conclusão. A partir da análise da literatura se notou que ainda há poucos estudos sobre o PNLD e o componente curricular Educação Física e que há "resistência" para utilização desses livros por parte dos professores. Compreende-se que a utilização dos livros didáticos pelo professor de Educação Física serve para dar direção, cabendo ao mesmo decidir a metodologia, as estratégias e o conteúdo que irá abordar, bem como a relevância que esses terão nas suas aulas.
\end{abstract}

Palavras-chave: Plano Nacional do Livro Didático. BNCC. Guia do Livro Didático. Educação Física Escolar. Prática Docente.

\begin{abstract}
The books that have a pedagogical character are called textbooks and appear as a form of presentation and organization of content that must be addressed in the teaching and learning process. These books have the contents, exercises, illustrations, examples, that is, multiple pedagogical applications that serve as a guide for the teacher. This article aims to contextualize a PNLD proposal in different curricular components in Elementary Education and to compare the Physical Education curricular component in relation to the others. Methodologically, it presents itself as a bibliographic review, which is the main object of analysis in this review and related literature. A research was structured from reading articles and documents that have PNLD as their main theme. The search for these articles was carried out in the Google Scholar and Scielo databases. 29 articles were selected, which were read and analyzed. For a selection of the articles indicated in this essay, the inclusion criteria considered: a) objectives, b) methods; and c) final considerations or conclusion. From the analysis of the literature, there are still few studies on the PNLD and the Physical Education curriculum component and that there is "resistance" to the use of these books by the teachers. It is understood that the use of textbooks by the Physical Education teacher serves as direction, being liable to the same to decide the methodology, the strategies and content that will address, as well as the relevance that these will have in the classes.
\end{abstract}

Keyword: National Textbook Plan. BNCC. Textbook Guide. School Physical Education. Teaching Practice.

\section{Introdução}

O Programa Nacional do Livro Didático (PNLD) é designado em avaliar e viabilizar os livros didáticos, pedagógicos e literários nas escolas públicas do Ensino Fundamental e Ensino Médio, elaborados em alternados ciclos trienais, sendo atualmente responsabilidade do Ministério da Educação. Tem por objetivo oferecer aos professores e alunos, de forma gratuita, os livros didáticos para auxiliar no processo de ensino e aprendizagem (CORRÊA; MEGGIOLARO; REIS, 2019).

O principal foco do PNLD é o Ensino Fundamental público, incluindo também as classes de alfabetização. $\mathrm{O}$ programa estabelece ao aluno o direito ao recebimento dos livros didáticos com conteúdo de cada componente curricular, como: Língua Portuguesa, Matemática, História, Geografia e Ciências (FREITAS; RODRIGUES, 2019).

Os livros que possuem caráter pedagógico são intitulados de livros didáticos e surgem como uma forma de apresentar e organizar os conteúdos, que serão abordados no processo de ensino e aprendizagem. Esses livros possuem os conteúdos, os exercícios, as ilustrações, as exemplificações, isto é, múltiplas aplicabilidades pedagógicas que servirão de guia para o professor (PORTO, 2019).

A primeira vez que o Governo se preocupou com os livros

1 Estudo apresentado como requisito parcial para obtenção de conceito na disciplina Núcleo de Ensino, Pesquisa e Extensão - NEPE em Pedagogia da Educação Física e Esporte do Curso de Licenciatura em Educação Física da Universidade Federal Rural do Rio de Janeiro. 
trabalhados dentro de sala de aula foi por meio do Decreto-lei $n^{\circ} 1006$, de 30/12/38 (BRASIL, 1939), porém não havia uma restrição ríspida referente ao conteúdo do livro, era apenas uma forma de realizar um filtro maior, compreendendo a falta de critério que estabelecia se o livro estava apto ou não para a faixa etária e o ano escolar ao qual seria implementado (BOLZAN; SANTOS, 2015). O fato é que o livro didático é influenciado pela ideologia da gestão que rege o Governo Federal, assim se tornam evidentes e intencionais as mudanças ocorridas no PNLD ao longo dos anos.

Por meio das mudanças ocorridas criou-se a Comissão Nacional do Livro Didático (CNLD) em 1938, que tinha o objetivo de produzir, de controlar e de circular os livros para todo o país, reduzindo neste período as obras circulantes no mercado editorial. Como estratégia para ter o controle da produção de conhecimento no Ensino Básico, durante o regime Vargas, foi implantada uma comissão em que os livros passaram a ser editados pelo Estado. Assim, o Governo tinha todo monopólio sobre o que era produzido para os alunos da rede de Ensino Básico do país (SOARES; ROCHA, 2005).

Com aproximação entre Brasil e Estados Unidos durante a Ditadura Militar, em 1966, foi realizada uma aliança entre o MEC e a Agência Norte-Americana para o Desenvolvimento Internacional (USAID), autorizando a institucionalização da Comissão do Livro Técnico Didático (COLTED). Este procedimento rejeitou os professores e as editoras, trazendo a responsabilidade do controle de produção somente da USAID (PINA, 2011).

Era comum professores escreverem sobre outros componentes curriculares, além da sua área de formação, entretanto, a partir da década de 1960 os livros didáticos começaram a ser escritos por especialistas de sua área, proporcionando maior qualidade nos livros distribuídos para o Brasil (SILVA, 2012).

Em 1971, o Instituto Nacional do Livro (INL), criado em 1937, um ano antes do CNLD, passa a arquitetar o Programa do Livro Didático para o Ensino Fundamental (PLIDEF). Porém em 1976, o INL é revogado e, assim, surge a Fundação Nacional do Material Escolar (FENAME) que repôs a autoria pela formulação do programa do livro didático. Em seguida, o Governo Federal começou a adquirir os livros por meio dos recursos do Fundo Nacional de Desenvolvimento da Educação (FNDE) e com as contribuições dos Estados (CASSIANO et al., 2007).

Em 1985, com o Decreto-lei $n^{\circ}$ 91.542, de 19/08/85, foram elaboradas algumas mudanças no PNLD como: a) os professores podiam recomendar os livros; b) os livros deveriam ser reaproveitados, assim os alunos não poderiam ficar com o livro para uso próprio, perdendo a função de capital cultural; e c) ampliação na oferta dos livros distribuídos para escolas públicas e comunitárias.

Entre 1993 e 1994 foram estipulados parâmetros para avaliação do livro didático, feitos pelo $\mathrm{MEC}$, mais especificamente, pela Fundação de Assistência ao Estudante (FAE) e pela Organização das Nações Unidas para a Educação, a Ciência e a Cultura (UNESCO), com a emissão do documento: "Definição de Critérios para avaliação dos Livros Didáticos”. Em 1996, foram acrescentados a esses parâmetros, critérios que validavam livros que abarcassem conceitos de ordem conceitual e de ordem política, em que os livros não poderiam conter qualquer ideologia que induzisse ao erro ou preconceito. Mais adiante, em 1999, foi adicionado outro critério de aprovação, o de natureza metodológica, que avaliava a coerência e a diversidade dos métodos de ensino e aprendizagem (BATISTA; ROJO; ZÚÑIGA, 2005).

Em 1997 houve o fim da Fundação de Assistência ao Estudante (FAE), e o encargo pela política de aplicação do PNLD foi cedido para o FNDE, deixando de ser somente para Ensino Fundamental e ampliando para todos os anos da Ensino Básico e todos os componentes curriculares. Em 2011, o PNLD alcança integralmente o Ensino Médio, juntamente com a Educação de Jovens e Adultos (CURY, 2009).

No ano de 2012, começou a distribuição de materiais digitais mostrando os avanços tecnológicos do PNLD, como: jogos educativos, infográficos, tudo enviado para escola em forma DVD e para as instituições que possuem acesso à internet foi disponibilizado um link no livro, para que pudessem ser realizados trabalhos nos computadores da escola, tornando as aulas mais interessantes e modernas (BRASIL, 2012).

Em 2017, foi aprovado o Decreto ${ }^{\circ}$ 9.099, em que o PNLD atuava no âmbito do Ministério da Educação, com a função de aquisição e distribuição dos livros e materiais didáticos, ficando a cargo do Governo Federal arcar com os custos. Entretanto, em março de 2018 foi validado o Decreto $n^{\circ} 9.304$, que deu origem ao Comitê Gestor do Fundo de Financiamento Estudantil (CG - Fies) e impôs competências ao FNDE, realizando uma parceria com instituições financeiras na área do Fundo de Financiamento Estudantil (Fies).

Diante disto, destacam-se os gastos elevados nas aquisições destes materiais, em função disso uma pesquisa sobre os últimos três anos expôs a quantidade de exemplares e o custo desta aquisição. Em 2017 foram comprados 152.351.763 exemplares para todo o Ensino Básico, custando em reais R\$ 1.295.910.769,73. No ano de 2018, apesar das empresas contribuírem com os gastos, o Decreto foi aprovado em março, período posterior a realização das compras dos livros, que custaram R\$ 1.467.232.112,09 adquirindo 153.899.147 exemplares. No ano de 2019, já com o capital privado foram investidos $\mathrm{R} \$$ 1.102.025.625,17 e 126.099.033 exemplares, diminuindo consideravelmente o gasto público com o livro didático (FNDE, 2020).

Posto isto, e tendo em vista a importância do PNLD, procurase ao longo deste artigo de revisão bibliográfica discorrer acerca das possibilidades e uso do livro didático no Ensino Básico, bem como da importância da sua implementação no contexto do componente curricular Educação Física. Assim, o 
presente artigo tem como objetivo contextualizar a proposta do PNLD em diferentes componentes curriculares no Ensino Fundamental e comparar o componente curricular Educação Física em relação aos outros.

\section{Desenvolvimento}

\subsection{Metodologia}

Este artigo se apresenta como uma revisão bibliografica, de cariz formativa e opinativa, que por meio da análise da literatura visa expandir o conhecimento acerca do PNLD no contexto do Ensino Fundamental e do componente curricular Educação Física. O principal objeto de análise nessa revisão é a literatura produzida sobre a temática, proporcionando maior entendimento sobre tal conhecimento.

Os artigos de revisão bibliográfica se caracterizam como um processo de pesquisa, em volta da literatura a respeito da temática/objeto de estudo, com intuito de proporcionar amplo entendimento acerca do objeto analisado. Nesse método de análise, o objeto de estudo é a literatura, necessária para compreensão e interpretação do corpus textual de conhecimento que possibilitará o esclarecimento da pesquisa.

A revisão bibliográfica de cariz opinativa, com base em Mancini e Sampaio (2006), é uma revisão do tipo em que o pesquisador analisa evidências sobre uma determinada temática ou assunto, sem a necessidade de seguir uma metodologia pré-definida. Neste tipo de revisão não se recorre, necessariamente, a procedimentos padronizados sistematização na seleção dos artigos, livros e/ou documentos que serão analisados - de busca bibliográfica, mas não prescinde de resumir, analisar e sintetizar informações relativas ao problema investigado.
Mesmo assim, esse tipo de pesquisa possibilita uma refexão crítica da literatura, do tipo opinativa, sobre a temática ao final da pesquisa (MANCINI; SAMPAIO, 2006), visto que se propõe discutir, analisar e sintetizar, com considerada veracidade e compromisso com as informações disponibilizadas na literatura dos artigos, livros e documentos legais analisados ao decorrer desta revisão.

A pesquisa foi estruturada a partir da leitura de artigos, livros e documentos que apresentam como tema principal o PNLD no contexto do Ensino Fundamental e do componente curricular Educação Física.

As consultas ao assunto investigado foram realizadas em duas bases de dados: Google Acadêmico e Scielo. Desta consulta, foram selecionados 29 artigos, que foram lidos, analisados e organizados no quadro abaixo. Para a seleção dos artigos apontados neste ensaio, o critério de inclusão considerou: a) objetivos, b) métodos; e c) considerações finais ou conclusão dos mesmos; que versavam sobre a proposta do PNLD e os componentes curriculares do Ensino Fundamental, especificamente, aqueles relacionados ao componente curricular Educação Física, conforme sistematizado abaixo no Quadro 1.

Também se recorre à análise documental de Emendas Constitucionais, de Resoluções, de Decretos-lei, da Base Nacional Comum Curricular (2017) e outros documentos de cunho normativo e legal no âmbito da Educação brasileira, assim como foram analisados livros e trabalhos acadêmicos que abordassem a atividade didático-pedagógica e sua relação com o PNLD na escolarização básica.

Tona-se relevante ressaltar que, em quase sua totalidade, as produções selecionadas e analisadas compreendem o período de 2014 a 2019.

Continua...

Quadro 1 - Artigos sobre a proposta do PNLD em diferentes Componentes Curriculares (CC) no Ensino Fundamental

\begin{tabular}{|c|c|c|c|c|c|c|}
\hline $\mathrm{CC}$ & Autores & Ano & Periódico & Objetivo & Método & Conclusão \\
\hline \multirow{3}{*}{ 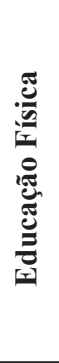 } & $\begin{array}{l}\text { Carlos e } \\
\text { Melo }\end{array}$ & 2018 & Motricidade & $\begin{array}{l}\text { Analisar os livros didáticos } \\
\text { para o ensino da Educação } \\
\text { Física Escolar } \\
\end{array}$ & $\begin{array}{l}\text { Análise } \\
\text { documental }\end{array}$ & $\begin{array}{l}\text { Os livros didáticos não podem ser } \\
\text { um limitador do fazer pedagógico }\end{array}$ \\
\hline & $\begin{array}{l}\text { Barroso e } \\
\text { Darido }\end{array}$ & 2017 & Pensar a Prática & $\begin{array}{l}\text { Identificar as possibilidades e } \\
\text { dificuldades da utilização dos } \\
\text { livros didáticos }\end{array}$ & $\begin{array}{l}\text { Análise de } \\
\text { conteúdo de } \\
\text { entrevistas }\end{array}$ & $\begin{array}{l}\text { O professor atuante precisa de um } \\
\text { tempo para se adaptar à utilização } \\
\text { do livro didático }\end{array}$ \\
\hline & $\begin{array}{l}\text { Bolzan e } \\
\text { Santos }\end{array}$ & 2015 & J. Phys. Educ. & $\begin{array}{l}\text { Analisar as propostas didático- } \\
\text { pedagógicas publicadas pelas } \\
\text { Secretarias Estaduais de } \\
\text { Ensino }\end{array}$ & $\begin{array}{l}\text { Revisão } \\
\text { bibliográfica }\end{array}$ & $\begin{array}{l}\text { Os livros didáticos para a Educação } \\
\text { Física devem refletir sobre o corpo, } \\
\text { a intencionalidade do movimento e } \\
\text { as práticas corporais }\end{array}$ \\
\hline \multirow{2}{*}{ : } & $\begin{array}{l}\text { Romano, } \\
\text { Schimiguel e } \\
\text { Fernandes }\end{array}$ & 2019 & $\begin{array}{l}\text { Rev. Ensino } \\
\text { Ciênc. Matem. }\end{array}$ & $\begin{array}{l}\text { Análise acerca da articulação } \\
\text { dos livros didáticos de } \\
\text { Matemática do PNLD e } \\
\text { as diretrizes no ensino da } \\
\text { Geometria }\end{array}$ & $\begin{array}{l}\text { Análise } \\
\text { documental }\end{array}$ & $\begin{array}{l}\text { Os livros didáticos devem } \\
\text { contemplar a BNCC, como previsto } \\
\text { pelo PNLD, todavia, é necessário } \\
\text { que ocorra a adaptação às mudanças } \\
\text { ao invés de aceitá-las }\end{array}$ \\
\hline & $\begin{array}{l}\text { Sturion e } \\
\text { Amaral Schio }\end{array}$ & 2019 & $\begin{array}{l}\text { Tangram - Rev. } \\
\text { Ed. Matemática }\end{array}$ & $\begin{array}{l}\text { Analisar as coleções de livros } \\
\text { didáticos de Matemática, } \\
\text { aprovados pelo PNLD } 2018\end{array}$ & $\begin{array}{l}\text { Análise } \\
\text { documental }\end{array}$ & $\begin{array}{l}\text { A maior parte das habilidades } \\
\text { sugeridas pela BNCC é } \\
\text { contemplada nos livros didáticos }\end{array}$ \\
\hline
\end{tabular}


Continua...

\begin{tabular}{|c|c|c|c|c|c|c|}
\hline \multirow{4}{*}{ 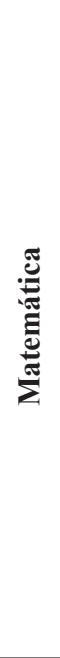 } & \begin{tabular}{|l} 
Azevedo, \\
Melo e \\
Siqueira \\
\end{tabular} & 2018 & Rev. Uniabeu & $\begin{array}{l}\text { Verificar como os gêneros } \\
\text { textuais são utilizados no } \\
\text { ensino da Matemática }\end{array}$ & $\begin{array}{l}\text { Análise } \\
\text { documental }\end{array}$ & $\begin{array}{l}\text { Os gêneros textuais favorecem } \\
\text { a comunicação e ampliação dos } \\
\text { conhecimentos matemáticos }\end{array}$ \\
\hline & $\begin{array}{l}\text { Pereira e } \\
\text { Conti }\end{array}$ & 2017 & Momentum & $\begin{array}{l}\text { Análise acerca do bloco de } \\
\text { conteúdos }\end{array}$ & $\begin{array}{l}\text { Revisão } \\
\text { bibliográfica } \\
\text { Estudos de } \\
\text { caso }\end{array}$ & $\begin{array}{l}\text { O livro didático poderia trazer mais } \\
\text { subsídios para a melhor prática } \\
\text { pedagógica dos professores }\end{array}$ \\
\hline & $\begin{array}{l}\text { Ribeiro e } \\
\text { Amaral }\end{array}$ & 2016 & $\begin{array}{l}\text { Rev. Educ. } \\
\text { Matem. }\end{array}$ & $\begin{array}{l}\text { Analisar o contexto dos } \\
\text { Objetos Educacionais Digitais } \\
\text { e do Guia do Livro Didático, } \\
\text { aprovado pelo PNLD sobre o } \\
\text { conhecimento matemático do } \\
\text { professor }\end{array}$ & $\begin{array}{l}\text { Análise } \\
\text { documental }\end{array}$ & $\begin{array}{l}\text { Torna-se essencial discutir o PNLD } \\
\text { e os Objetos Educacionais Digitais } \\
\text { nos livros didáticos da Matemática }\end{array}$ \\
\hline & Silva & 2015 & $\begin{array}{l}\text { Rev. Paran. } \\
\text { Educ. Matem. }\end{array}$ & \begin{tabular}{|l|} 
Investigar a representação de \\
triângulos nas coleções de \\
livros didáticos propostos pelo \\
PNLD
\end{tabular} & $\begin{array}{l}\text { Análise } \\
\text { documental }\end{array}$ & $\begin{array}{l}\text { Há pouca variedade de } \\
\text { representações de triângulos nos } \\
\text { livros didáticos propostos }\end{array}$ \\
\hline \multirow{5}{*}{ 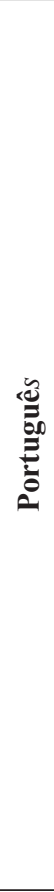 } & $\begin{array}{l}\text { Albuquerque } \\
\text { e Ferreira }\end{array}$ & 2019 & $\begin{array}{l}\text { Ensaio: Aval. } \\
\text { Políticas Púb. } \\
\text { Educ. }\end{array}$ & $\begin{array}{l}\text { Analisar as mudanças nos } \\
\text { critérios } \\
\text { de avaliação dos livros } \\
\text { didáticos de alfabetização em } \\
\text { diferentes } \\
\text { edições do PNLD }\end{array}$ & $\begin{array}{l}\text { Análise } \\
\text { documental }\end{array}$ & $\begin{array}{l}\text { O professor pode ser flexível e } \\
\text { ter autonomia ao utilizar o livro } \\
\text { didático }\end{array}$ \\
\hline & $\begin{array}{l}\text { Nogueira, } \\
\text { Silva e } \\
\text { Colombo }\end{array}$ & 2018 & $\begin{array}{l}\text { Educ. } \\
\text { Realidade }\end{array}$ & $\begin{array}{l}\text { Analisar como as propostas } \\
\text { do PNLD podem constituir } \\
\text { e impactar o trabalho do } \\
\text { professor }\end{array}$ & $\begin{array}{l}\text { Análise das } \\
\text { documental }\end{array}$ & $\begin{array}{l}\text { O PNLD determina o modo de } \\
\text { elaboração dos conteúdos, tirando a } \\
\text { interlocução real do professor }\end{array}$ \\
\hline & $\begin{array}{l}\text { Bertotti e } \\
\text { Mendes }\end{array}$ & 2018 & $\begin{array}{l}\text { Rev. Leia } \\
\text { Escola }\end{array}$ & $\begin{array}{l}\text { Investigar como a Linguística } \\
\text { é trabalhada nos livros } \\
\text { didáticos propostos pelo } \\
\text { PNLD }\end{array}$ & $\begin{array}{l}\text { Análise } \\
\text { coleções } \\
\text { de livros } \\
\text { didáticos } \\
\text { propostas } \\
\text { pelo PNLD }\end{array}$ & $\begin{array}{l}\text { O livro didático não foi investigado } \\
\text { como um todo, apenas os conteúdos } \\
\text { de linguística através dos gêneros } \\
\text { textuais }\end{array}$ \\
\hline & $\begin{array}{l}\text { Freitas e } \\
\text { Vazquez. }\end{array}$ & 2017 & $\begin{array}{l}\text { Rev. Práticas } \\
\text { Educ. Básica }\end{array}$ & $\begin{array}{l}\text { Analisar o edital do PNLD } \\
\text { para as coleções de Língua } \\
\text { Portuguesa e Língua Inglesa }\end{array}$ & $\begin{array}{l}\text { Análise } \\
\text { documental } \\
\text { do PNLD }\end{array}$ & $\begin{array}{l}\text { O mercado editorial envolvido no } \\
\text { PNLD contribui para colocar o livro } \\
\text { didático como um solucionador de } \\
\text { problemas }\end{array}$ \\
\hline & $\begin{array}{l}\text { Ribeiro, } \\
\text { Paulino e } \\
\text { Carvalho }\end{array}$ & 2015 & $\begin{array}{l}\text { Web Rev. Ling. } \\
\text { Educ. Memória }\end{array}$ & $\begin{array}{l}\text { Analisar atividades dos livros } \\
\text { didáticos como guia do livro } \\
\text { didático PNLD }\end{array}$ & $\begin{array}{l}\text { Análise } \\
\text { documental } \\
\text { do PNLD }\end{array}$ & $\begin{array}{l}\text { O professor deve ter a autonomia } \\
\text { para escolher um material didático }\end{array}$ \\
\hline \multirow{5}{*}{ 晋 } & $\begin{array}{l}\text { Queiroz } \\
\text { Júnior e } \\
\text { Rocha }\end{array}$ & 2019 & $\begin{array}{l}\text { Rev. Favor } \\
\text { Igualdade } \\
\text { Racial }\end{array}$ & $\begin{array}{l}\text { Analisar as mudanças } \\
\text { realizadas nos livros didáticos } \\
\text { referentes à lei } 10.639 / 2003\end{array}$ & $\begin{array}{l}\text { Análise } \\
\text { bibliográfica. }\end{array}$ & $\begin{array}{l}\text { Com o passar dos anos a inserção } \\
\text { de conteúdos de história, cultura } \\
\text { africana e afro-brasileira tornou-se } \\
\text { mais recorrente nos livros }\end{array}$ \\
\hline & $\begin{array}{l}\text { Gonçalves e } \\
\text { Germinari }\end{array}$ & 2019 & Hist. Ensino & $\begin{array}{l}\text { Discutir propostas no Ensino } \\
\text { Fundamental de História, a } \\
\text { partir do PNLD do campo }\end{array}$ & $\begin{array}{l}\text { Revisão } \\
\text { bibliográfica }\end{array}$ & $\begin{array}{l}\text { Os volumes do livro não apresentam } \\
\text { atividades e nem proporciona a } \\
\text { construção de relações com o tempo } \\
\text { no espaço rural }\end{array}$ \\
\hline & $\begin{array}{l}\text { Tamanini e } \\
\text { Noronha }\end{array}$ & 2019 & Rev. Teias & $\begin{array}{l}\text { Analisar comparativamente } \\
\text { alguns conteúdos de História } \\
\text { após as diretrizes da BNCC }\end{array}$ & $\begin{array}{l}\text { Análise } \\
\text { comparativa }\end{array}$ & $\begin{array}{l}\text { O livro da BNCC transmite } \\
\text { uma visão mais macro sobre os } \\
\text { conteúdos, não se preocupando com } \\
\text { as reflexões críticas dos alunos }\end{array}$ \\
\hline & $\begin{array}{l}\text { Centeno, } \\
\text { Caratt } i\end{array}$ & 2019 & RELAcult & $\begin{array}{l}\text { Analisar o livro didático } \\
\text { dentro de sala de aula no } \\
\text { Ensino Médio e Ensino } \\
\text { Fundamental }\end{array}$ & $\begin{array}{l}\text { Análise } \\
\text { do livro } \\
\text { didático }\end{array}$ & $\begin{array}{l}\text { O livro didático favorece um ensino } \\
\text { restrito que interfere na autonomia } \\
\text { do professor }\end{array}$ \\
\hline & $\begin{array}{l}\text { Miranda, } \\
\text { Luca }\end{array}$ & 2004 & Rev. Bras. Hist. & $\begin{array}{l}\text { Analisar livros de história, } \\
\text { investigando o saber histórico } \\
\text { escolar sobre temáticas } \\
\text { centrais do componente } \\
\text { curricular e como isso é } \\
\text { ensinado através deste material }\end{array}$ & $\begin{array}{l}\text { Análise } \\
\text { dos livros } \\
\text { anteriores } \\
\text { até } 2005\end{array}$ & $\begin{array}{l}\text { Os livros são construídos não para } \\
\text { o aprendizado, mas sim para uma } \\
\text { avaliação do programa nacional do } \\
\text { livro didático }\end{array}$ \\
\hline
\end{tabular}


Continuação.

\begin{tabular}{|c|c|c|c|c|c|c|}
\hline \multirow{5}{*}{ 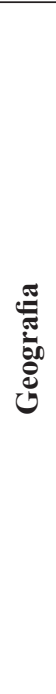 } & Santos e Luiz & 2019 & $\begin{array}{l}\text { Rev. Geog. } \\
\text { (Londrina) }\end{array}$ & $\begin{array}{l}\text { Discutir o ensino de relevo } \\
\text { nos anos finais do Ensino } \\
\text { Fundamental através do livro } \\
\text { didático }\end{array}$ & $\begin{array}{l}\text { Análise } \\
\text { bibliográfica }\end{array}$ & $\begin{array}{l}\text { Os conteúdos presentes nos livros } \\
\text { devem ser aprimorados e discutidos, } \\
\text { pois o ensino de geografia deve } \\
\text { integrar as necessidades do mundo } \\
\text { contemporâneo e dos estudantes }\end{array}$ \\
\hline & Deon e Callai & 2018 & $\begin{array}{l}\text { Rev. Bras. } \\
\text { Educ. Geog. }\end{array}$ & $\begin{array}{l}\text { Discutir o conceito de } \\
\text { cidadania através do livro } \\
\text { didático de Geografia }\end{array}$ & $\begin{array}{l}\text { Análise } \\
\text { documental }\end{array}$ & $\begin{array}{l}\text { O conceito de cidadania está oculto } \\
\text { no livro didático de geografia }\end{array}$ \\
\hline & $\begin{array}{l}\text { Katuta e } \\
\text { Déak }\end{array}$ & 2017 & Terra Livre & $\begin{array}{l}\text { Apresentar histórico do livro } \\
\text { didático e a relação docente } \\
\text { com este material }\end{array}$ & $\begin{array}{l}\text { Análise de } \\
\text { conteúdo }\end{array}$ & $\begin{array}{l}\text { Investimento em políticas } \\
\text { educacionais de formação dos } \\
\text { professores das séries iniciais do } \\
\text { Ensino Fundamental }\end{array}$ \\
\hline & $\begin{array}{l}\text { Carvalho e } \\
\text { Veloso Filho }\end{array}$ & 2015 & $\begin{array}{l}\text { Caminhos } \\
\text { Geog. }\end{array}$ & $\begin{array}{l}\text { Avaliar o livro de Geografia de } \\
2013 \text { a } 2015\end{array}$ & $\begin{array}{l}\text { Pesquisa } \\
\text { bibliográfica }\end{array}$ & $\begin{array}{l}\text { O livro de geografia apresenta os } \\
\text { conceitos corretos e está atualizado } \\
\text { com a literatura }\end{array}$ \\
\hline & Maciel & 2014 & $\begin{array}{l}\text { Pesq. Rev. } \\
\text { Estudos Pesq. } \\
\text { Ensino Geog. }\end{array}$ & $\begin{array}{l}\text { Verificar a qualidade do livro } \\
\text { de Geografia distribuído nas } \\
\text { escolas }\end{array}$ & $\begin{array}{l}\text { Análise } \\
\text { documental }\end{array}$ & $\begin{array}{l}\text { Os livros de geografia apresentam } \\
\text { conceitos incorretos e aumentam o } \\
\text { questionamento sobre as correções } \\
\text { por parte das editoras }\end{array}$ \\
\hline \multirow{5}{*}{ 产 } & $\begin{array}{l}\text { Moreira e } \\
\text { Strieder }\end{array}$ & 2019 & $\begin{array}{l}\text { Rev. Bras. Inic. } \\
\text { Cient. }\end{array}$ & $\begin{array}{l}\text { Discutir Sobre Educação } \\
\text { Alimentar }\end{array}$ & $\begin{array}{l}\text { Análise } \\
\text { documental }\end{array}$ & $\begin{array}{l}\text { Atitude Conceitual Distante Das } \\
\text { Atitudes Permanentes }\end{array}$ \\
\hline & Souza & 2019 & Rev. Horizonte & $\begin{array}{l}\text { Analisar a visualidade dos } \\
\text { livros didáticos de Ciências }\end{array}$ & $\begin{array}{l}\text { Análise } \\
\text { dos livros } \\
\text { didáticos } \\
\text { de ciências } \\
\text { no Ensino } \\
\text { Fundamental }\end{array}$ & $\begin{array}{l}\text { As imagens fotográficas contribuem } \\
\text { para promover a saúde e o bem- } \\
\text { estar }\end{array}$ \\
\hline & $\begin{array}{l}\text { Santos, } \\
\text { Schneider e } \\
\text { Justina }\end{array}$ & 2019 & $\begin{array}{l}\text { Gôndola, } \\
\text { Enseñanza } \\
\text { Aprend. Cienc. }\end{array}$ & $\begin{array}{l}\text { Evidenciar a existência } \\
\text { epistemológica sobre o tema } \\
\text { "água" nos livros didáticos }\end{array}$ & $\begin{array}{l}\text { Estudo epis- } \\
\text { temológico } \\
\text { em livros de } \\
\text { ciências de } \\
2017\end{array}$ & $\begin{array}{l}\text { Estudos relacionados a obstáculos } \\
\text { epistemológicos contribuem para o } \\
\text { ensino aprendizagem }\end{array}$ \\
\hline & $\begin{array}{l}\text { Silva, Alves } \\
\text { e Andrade }\end{array}$ & 2019 & Rev. Triângulo & $\begin{array}{l}\text { Apresentar o resgate histórico } \\
\text { dos currículos de Ciências e } \\
\text { Química }\end{array}$ & $\begin{array}{l}\text { Análise } \\
\text { documental }\end{array}$ & $\begin{array}{l}\text { Os conteúdos curriculares seguem } \\
\text { as tendências mundiais de ensino } \\
\text { contextualizado }\end{array}$ \\
\hline & $\begin{array}{l}\text { Coutinho, } \\
\text { Ruppenthal e } \\
\text { Adaime }\end{array}$ & 2019 & $\begin{array}{l}\text { Rev. Ensino } \\
\text { Ciênc. Matem. }\end{array}$ & $\begin{array}{l}\text { Analisar o conteúdo do livro } \\
\text { de Ciências }\end{array}$ & $\begin{array}{l}\text { Análise } \\
\text { do livro } \\
\text { didático }\end{array}$ & $\begin{array}{l}\text { O ensino ambientalismo contribui } \\
\text { para um potencial exploratório da } \\
\text { mesma aprendizagem }\end{array}$ \\
\hline
\end{tabular}

\subsection{Discussão}

A seguir serão apresentados os dados provenientes da análise dos 29 artigos. A partir do objetivo deste estudo e da análise dos artigos, os principais eixos temáticos abordados foram organizados em três tópicos inter-relacionados e complementares. O primeiro trata acerca da proposta do PNLD e sua relação com a BNCC, o segundo da proposta do PNLD para o Ensino Fundamental e o componente curricular Educação Física e o terceiro da contribuição do PNLD para o trabalho docente no contexto da sala de aula.

\subsubsection{A proposta do PNLD e sua relação com a BNCC}

A Base Nacional Comum Curricular (BNCC) é caracterizada por um documento normativo aplicado à Educação Básica (Educação Infantil, Ensino Fundamental e Ensino Médio), no âmbito federal, estadual e municipal, visando o desenvolvimento global do aluno (BNCC, 2017).

A etapa mais longa da Educação Básica é o Ensino Fundamental, possuindo nove anos de duração, sendo o período em que há mais mudanças e atividades na vida dos alunos. Essas atividades são realizadas por diferentes linguagens. Na BNCC, a área de Linguagens é constituída por quatro componentes curriculares, sendo esses: Educação Física, Arte, Língua Portuguesa e Língua Inglesa (BNCC, 2017).

Com a implementação da BNCC, é necessário que o PNLD reformule os conteúdos presentes nos livros didáticos para que se acompanhe a proposta deste novo documento (ROMANO; SHIMGUEL; FERNANDES, 2019). Ademais, Tamanine e Noronha (2019) ratificam que os livros são mal utilizados, pois transmitem uma visão generalizada dos conteúdos, de forma que os alunos não são estimulados a 
construir pensamentos e ações críticas sobre os assuntos abordados, limitando o processo de ensino e aprendizagem.

A BNCC traz conteúdos da Educação Física como, por exemplo, a educação alimentar um assunto obrigatório no Ensino Fundamental, assim, obrigatoriamente, os livros didáticos de Ciências designados a este público devem apresentar este tema. O conteúdo sobre educação alimentar é considerado de extrema importância, pois é nesta faixa etária que o aluno deve ter controle sobre o seu corpo e construir hábitos saudáveis (MOREIRA; STRIEDER, 2019). Esse é um dos pontos principais a serem observados no PNLD, que deve seguir a base proposta pela BNCC, evitando causar defasagem nos conteúdos dos livros para o Ensino Básico.

Além disso, encontram-se poucas informações nos livros didáticos sobre determinado conteúdo e até mesmo informações errôneas para os alunos. Como, por exemplo, o estudo de Santos, Schneider e Justina (2019) que relata sobre livros do sexto ano do Ensino Fundamental que apontam poucas informações sobre a "água", não exemplificam de forma clara para que consigam obter a informação correta dos conteúdos, estabelecendo uma realidade distante e dificultando o entendimento dos alunos.

Ainda, Silva, Alves e Andrade (2019) confirmam que os conteúdos do livro didático atendem às tendências mundiais para que possam contribuir na educação brasileira. Assim, o livro didático atua como eminente auxiliador do trabalho docente e deve servir de auxílio para inserir as competências propostas pela BNCC, visto que este é um documento normativo e cabe ao professor ter consciência ao transmitir esses conteúdos aos alunos. Ademais, ambos buscam fornecer formas alternativas de desenvolver o conhecimento e aprendizagem no contexto da aula.

A BNCC, em seu documento, diz que as escolas que disponibilizam laboratórios facilitam o processo de ensino e aprendizagem, de maneira que os conteúdos seriam fixados com mais facilidade, pois os alunos teriam a oportunidade de vivenciá-los na prática. Ainda, o PNLD dispõe de materiais didáticos virtuais diferenciados para serem utilizados nas escolas que possuem essa estrutura para esse tipo de proposta pedagógica (teórico-prática). Assim, a escola que possui seu próprio laboratório para auxiliar os alunos, contribuindo positivamente com o potencial exploratório da aprendizagem do ensino destes (COUTINHO; RUPPENTHAI; ADAIME, 2019).

Mesmo com essas discordâncias entre os seus conteúdos, a BNCC e o PNLD caminham juntos na produção do conhecimento para a Educação Básica Nacional, buscando fornecer ferramentas para auxiliar o professor na execução do seu trabalho em sala de aula (STURION; AMARAL SCHIO, 2019).

\subsubsection{O PNLD e a Educação Física no Ensino Fundamental}

A partir da nova concepção estabelecida pela LDB de 1996, a Educação Física deveria trabalhar com as demais práticas corporais e não apenas com o esporte. Com suas propostas curriculares ampliadas para a cultura corporal do movimento, o professor contribui para a formação integral do aluno através da dança, da ginástica geral, de jogos, de lutas e do próprio esporte. Com este espaço, o professor, principal agente promotor da cidadania na escola, tem o dever de aprofundar ensinamentos objetivando atitudes de respeito mútuo, dignidade, solidariedade, afetividade e coletividade (GUIMARÃES et al., 2001).

OprofessordeEducaçãoFísicaéquempossuiespecialização para trabalhar objetivos, conteúdos, procedimentos de ensino e avaliação adequados e sistematizados de forma que o aluno alcance o desenvolvimento da forma mais eficaz. Contudo, a sua presença e participação é fundamental e indispensável na mediação do processo de ensino-aprendizagem (MAGALHÃES; KOBAL; GODOY, 2007).

A utilização do livro didático como ferramenta pedagógica possibilita o acesso de uma maior quantidade de informações, auxiliando o professor e acrescentando outras informações sobre o conteúdo que será desenvolvido no contexto da aula com os alunos. Contribui para o professor que possui domínio de um determinado conteúdo e, também, aos que apresentam pouco conhecimento, sendo assim, uma importante ferramenta para o planejamento e a intervenção pedagógica no contexto da aula de qualquer componente curricular (ALBURQUERQUE; FERREIRA, 2019; CENTENO; CARATTI, 2019).

Segundo Barroso e Darido (2017), é necessário que ocorra a reflexão sobre o uso do livro didático e o componente curricular Educação Física. Muitos professores têm resistência na utilização dos livros e optam em não os utilizar quando disponíveis, por acreditar que se tornariam dependentes deles, e acreditam que a obediência fiel a esse tipo de material levaria à "desprofissionalização docente". Entretanto, a aplicação desse instrumento pedagógico serve como apoio de acordo com as necessidades dos conteúdos, que serão desenvolvidos com os alunos.

A ausência do componente curricular Educação Física no PNLD e a necessidade de orientar a prática docente resultaram em iniciativas das redes de ensino em produzir materiais didático-pedagógicos correlacionando a Educação Física com os Parâmetros Curriculares Nacionais, promovendo significado à Educação Física Escolar e tratando de maneira pedagógica as manifestações da cultura corporal de movimento, os aspectos sociais, culturais e históricos (BOLZAN; SANTOS, 2015).

Apesar de não haver muitos estudos relacionados com o PNLD e a Educação Física no Ensino Fundamental, Carlos e Melo (2018) relatam que a Educação Física Escolar também possui uma matriz curricular ampla e consolidada cientificamente, e que os conteúdos dos livros didáticos devem ser organizados de acordo com os anos do Ensino Fundamental e não propostos de uma forma aleatória, como é sugerido em algumas bases documentais legais.

Posto isto, torna-se relevante ressaltar que o componente 
curricular Educação Física foi inserido no PNLD 2020. Como dito anteriormente, a Educação Física se insere na área de Linguagens, valoriza o trabalho com unidades temáticas como brincadeiras e jogos, esportes, ginásticas, lutas, danças e práticas corporais de aventura, dentro de quatro ciclos: 1) $1^{\circ}$ e $2^{\circ}$ anos; 2) $3^{\circ}$ ao $5^{\circ}$ ano; 3) $6^{\circ}$ e $7^{\circ}$ anos; e 4) $8^{\circ}$ e $9^{\circ}$ anos.

Assim, os ciclos se diferenciam pelos "critérios de progressão do conhecimento, tais como elementos específicos das diferentes práticas corporais, as características dos sujeitos e os contextos de atuação" (BNCC, 2017, p. 217); nos quais a BNCC se apoiou para organizar os conhecimentos e as habilidades específicas que devem compor os currículos do projeto político pedagógico do Ensino Fundamental.

Sendo assim, o "Guia Digital" do PNLD 2020 tem por objetivo contribuir para a escolha dos livros didáticos que os professores utilizarão em suas aulas e mostra a composição dos livros em relação aos anos finais do Ensino Fundamental. Entre os componentes curriculares propostos pelo Guia Digital, a Educação Física está presente com dois livros didáticos (BRASIL, 2020).

O primeiro livro didático adotado, intitulado "Manual do Professor para a Educação Física" de autoria de Roselise Stallivieri e Diego Berton se apresenta como um manual para o professor de Educação Física em um único volume, organizado em: a) Orientações Gerais; b) Orientações Específicas; e c) Propostas de Atividades. Possui como destaque a cultura corporal de movimento e atividades propostas a partir das abordagens críticas, sistêmicas e culturais da Educação Física. O livro traz consigo o processo de avaliação diagnóstica e aborda a inclusão e interdisciplinaridade. As Orientações Específicas e Propostas de Atividades se dividem entre $6^{\circ}$ e $7^{\circ}$ ano com as unidades temáticas brincadeiras e jogos, esportes, ginásticas, danças, lutas e práticas corporais de aventura e $8^{\circ} \mathrm{e}$ $9^{\circ}$ ano com as unidades temáticas esportes, ginásticas, danças, lutas e práticas corporais de aventura, sendo atividades com maior nível de complexibilidade. O livro oferece recursos teóricos e práticos para o planejamento e organização da Educação Física escolar com o intuito de garantir que as unidades temáticas propostas pela BNCC sejam desenvolvidas com os alunos (STALLIVIERI; BERTON, 2018).

O segundo livro, intitulado "Práticas Corporais - Educação Física" de autoria de Osmar Moreira de Souza Junior, Laercio Claro Pereira Franco, Fernanda Moreto Impolcetto, André Luis Ruggiero Barroso, Amarilis Oliveira Carvalho, Aline Fernanda Ferreira Vargas, Irlla Karla dos Santos Diniz, Suraya Cristina Darido da Cunha se apresenta em volume único e está organizado em duas partes. A primeira parte destaca a adição da Educação Física na área de Linguagens e aborda questões como a trajetória histórica da Educação Física, além de teorias mais recentes da área, como a cultura corporal de movimento e as competências propostas pela BNCC. A segunda parte se destaca por diversificar estratégias didáticopedagógicas, contribuindo para o melhor planejamento do professor de Educação Física. O livro acompanha um material digital e um material digital audiovisual, que funciona como um complemento para a ampliação e compreensão dos conceitos e conhecimentos propostos (DARIDO et al., 2018).

Ainda, o PNLD 2020 determina que a obra deve ser organizada em volume único, que atenda do $6^{\circ}$ ao $9^{\circ}$ ano. $\mathrm{O}$ material didático para Educação Física para o segundo ciclo do Ensino Fundamental é uma das novidades e será composto de manual impresso disponível somente para o professor.

\subsubsection{O PNLD e sua relação com o Trabalho Docente}

O livro didático, atualmente, devido ao seu uso contínuo por alunos e professores, ainda é o recurso pedagógico mais usual nas escolas, podendo ser o único material disponível durante as aulas (QUEIROZ JUNIOR; ROCHA, 2019). Todavia, a aplicação para o uso do livro didático não depende apenas da decisão docente, e sim de políticas educacionais (KATUTA; DÉAK, 2017).

Considerando a importância desse material para o uso no Ensino Básico, especificamente no Ensino Fundamental, os critérios de avaliação para a elaboração dos livros didáticos foram aprimorados ao longo do tempo, resultando em um diversificado e extenso quadro relacionado com os saberes históricos e pedagógicos, mas ocasionalmente com ausência de conteúdos importantes (DEON; CALLAI, 2018; MIRANDA; LUCA, 2004).

O conteúdo dos livros didáticos é objeto de análise da maioria dos artigos encontrados sobre os assuntos que permeiam a temática deste estudo. Diante dessa observa-se a coerência entre a necessidade e a oferta do conteúdo abordado em diferentes componentes curriculares para os anos do Ensino Fundamental. Os conteúdos devem ser aprimorados de acordo com as necessidades dos alunos e da atualidade, de modo que se mantenham próximos da realidade, assim como retificados e melhor averiguados antes que sejam distribuídos às escolas de todo o país (GONÇALVES; GERMINARI, 2019; SANTOS; LUIZ, 2019; CARVALHO; VELOSO FILHO, 2015; MACIEL, 2014).

A diversidade de gêneros textuais, assim como materiais digitais complementares aos livros didáticos auxilia na compreensão e estimula a aprendizagem (SOUZA, 2019; AZEVEDO; MELO; SIQUEIRA, 2018; BERTOTTI; MENDES, 2018; RIBEIRO; AMARAL, 2016). Alguns dos livros explorados, mesmo que atendessem as necessidades gerais, obtiveram ressalvas pela falta de aprofundamento no conjunto de conceitos e ideias que, consequentemente, desfalcavam o aprendizado ou não facilitavam a compreensão (PEREIRA; CONTI, 2017; SILVA, 2015).

O PNLD se apresenta como o único capaz de ditar o conteúdo ensinado nas escolas públicas, restringindo a aula ao que é indicado nos livros com a justificativa de alcançar uma educação igual para todos (CENTENO; CARATTI, 2019; NOGUEIRA; SILVA; COLOMBO, 2018). Para que não ocorra desvalorização na atuação profissional, o professor deve ser flexível e ter autonomia para escolher um material didático, 
não só com os livros impressos e materiais convencionais, mas também com os Objetos Educacionais Digitais (OED), que são aditivos do PNLD. Apesar de um ótimo recurso, requer o mesmo posicionamento crítico do professor ao selecionar o que será utilizado em suas aulas (ALBUQUERQUE; FERREIRA, 2019; RIBEIRO; AMARAL, 2016; RIBEIRO; PAULINO; CARVALHO, 2015).

A partir deste ponto se entende que a utilização de livros didáticos encara uma dicotomia entre: os professores que gostariam de ter mais voz nas decisões de suas aulas e os professores submissos, que por vezes são fruto do próprio sistema, que passa a tratar o livro didático como solucionador de problemas (FREITAS; VAZQUEZ, 2017).

\section{Conclusão}

A partir da análise da literatura notou-se que ainda há poucos estudos sobre o PNLD e sua relação com a BNCC no que concerne o componente curricular Educação Física, quando comparado com os outros componentes curriculares do Ensino Básico; possivelmente, pelo fato do componente curricular Educação Física não estar presente no PNLD até o ano de 2019.

Compreende-se ao longo deste artigo a importância e necessidade de um material didático sistematizado e organizado para orientar o planejamento dos professores de Educação Física, entretanto, compartilha-se da ideia de que o componente curricular Educação Física necessita de um manual didático diferenciado dos outros componentes em função da ampla diversidade do conteúdo oriundo das diversas manifestações da cultura corporal de movimento, historicamente e culturalmente constituída no território nacional e, por isso, merece um olhar diferenciado quando se fala em organização da proposta curricular para o Ensino Básico.

Apensar da dificuldade em sistematizar e organizar esta gama de conteúdo, compreende-se que um livro didático tem mais a contribuir que atrapalhar o planejamento e a intervenção pedagógica dos professores de Educação Física, mas óbvio, tal fato dependerá da forma como o livro didático será implementado pelos professores no contexto das suas aulas. Cabendo ao professor de Educação Física aprender a utilizar o livro didático no planejamento das aulas, pois é o mesmo, quem ensina, aprende, faz mediações, está sempre em contato com o alunado.

Em se tratando do papel do professor e a utilização do livro didático se torna relevante considerar a autonomia docente para selecionar os conteúdos que mais se adequarão a proposta da sua aula, isto é, não o utilizando como uma mera "receita de bolo".

No que concerne a proposta do PNLD, objeto de análise deste artigo, compreende-se que este traz contribuições e avanços significativos para esta área no ano vindouro de 2020. A priori, por ser um material didático pioneiro e até então inexistente após publicada a BNCC, a proposta dos dois livros didáticos adotados pelo PNLD 2020 apresenta debates, sugestões de pesquisas, atividades etc., e por levantar questões em seu cerne, discussões que extrapolam do que habitualmente são tratadas nas aulas de Educação Física.

Contudo, compreende-se que o livro didático, independente do componente curricular, não supre todas as necessidades, dificuldades e problemáticas que rotineiramente surgem no contexto das aulas, em voga neste artigo as aulas de Educação Física. Todavia, é um material didático, que serve de orientação para o planejamento e, quando bem utilizado e adequado a realidade dos alunos, pode vir a compensar parte destas, rompendo com barreiras sociais, culturais e econômicas das distintas regiões do país.

Por fim, compreende-se que o livro didático serve como uma ferramenta pedagógica para auxílio do professor e quando presente nas escolas, ainda gera uma resistência em sua utilização decorrente do entendimento apenas da concepção procedimental da Educação Física, esse material deve ser tratado como mais um projeto adotado pela escola como os definidos no Projeto Político Pedagógico. Assim, o livro didático surge não como um "vilão e/ou mocinho" do PNLD, mas sim como uma ferramenta para auxiliar e orientar o planejamento e a intervenção pedagógicas do professor, tanto para o experiente como para o iniciante, isto é, servindo como uma bússola e cabe ao professor decidir a sequência de aplicação, a quantidade de conteúdo que irá abordar e a relevância que o mesmo terá para os seus alunos.

\section{Referências}

ALBUQUERQUE, E.B.C; FERREIRA, A.T.B. Programa nacional de livro didático (PNLD): mudanças nos livros de alfabetização e os usos que os professores fazem desse recurso em sala de aula. Ensaio Aval. Politicas Públicas Educ., v.27, n.103, p.250-270, 2019. doi: https://doi.org/10.1590/s010440362019002701617

AZEVEDO, M.C.; MELO, E.A.S.; SIQUEIRA, A.S. Livros didáticos de matemática de sexto e sétimo ano do plano nacional de livros didáticos 2017-2019: uma análise da utilização de gêneros textuais a partir das versões iniciais da base nacional comum curricular. Rev. Uniabeu, v.11, n.29, p.311-335, 2018.

BARROSO, A.L.R.; DARIDO, S.C. O livro didático na educação física escolar: visão de professores e alunos. Pensar a Prática, v.20, n.3, p.488-502, 2017.

BATISTA, A.A.G.; ROJO, R.; ZÚÑIGA, N.C. Produzindo livros didáticos em tempo de mudança (1999-2002). In: COSTA VAL, M.G.; MARCUSCHIL. B. Livros didáticos de língua portuguesa: letramento e cidadania. São Paulo: Autêntica, 2005. p.47-72.

BERTOTTI, K.S.A.L.; MENDES, R.M. Análise linguística a partir de gêneros no livro didático de língua portuguesa: uma visão contrastiva. Rev. Leia Escola, v.17, n.2, p.32-41, 2018.

BOLZAN, É.; SANTOS, W. Propostas didático-pedagógicas e suas projeções para o ensino da educação física. J. Phys. Educ., v.26, n.1, p.43-57, 2015.

BRASIL. Decreto, n $\mathrm{n}^{\circ} 91.542$ de 19 de agosto de 1985. Institui o Programa do Livro Didático, dispõe sobre sua execução e dá outras providências. Diário oficial da União: seção 1, Brasília, DF, n.6, p. 12.178, 20 agosto 1985. 
BRASIL. Educação Física: Guia Digital PNLD 2020. Disponível em: $\quad<$ https://pnld.nees.com.br/pnld_2020/componentecurricular/pnld2020-educacao-fisica>. Acesso em: 6 jan. 2020.

BRASIL. Ministério da Educação. Base Nacional Comum Curricular: ensino fundamental. Brasília: MEC/SEF, 2017.

CARLOS, C.U.B.; MELO, J.P. Livro didático em educação física: as experiências públicas de Joao Pessoa e do Paraná. Motricidade, v.14, p.72-78, 2018. doi: 10.6063/motricidade.16241

CARVALHO, D.R.P.; VELOSO FILHO, F.A.; PNLD e o processo de avaliação: iguais do livro didático de geografia (2013-2015). Caminhos de Geografia, v.16, n.55, p. 114-127, 2015.

CASSIANO, C. C. F. et al. O mercado do livro didático no Brasil: da criação do Programa Nacional do Livro Didático (PNLD) à entrada do capital internacional espanhol (1985-2007). São Paulo: PUC/SP, 2007.

CENTENO, Y.F.; CARATTI, J.M. Reflexões sobre o uso do livro didático nas aulas de História (ensino fundamental e ensino médio). RELACult, v.5, n.4, p.1-9, 2019. doi: 10.23899/relacult. v5i4.1216

CORRÊA, M.L.; MEGGIOLARO, G.P.; REIS, A.Q.M. Abordagem do conteúdo de frações a partir do Programa Nacional do Livro Didático. Rev. Ensino Ciênc. Matem., v.10, n.6, p.21-38, 2019.

COUTINHO, C.; RUPPENTHAL, R.; ADAIME, M.B. Estimulando a formação do sujeito ecológico em alunos de ensino fundamental: contribuições dos livros didáticos de ciências. Rev. Ensino Ciênc. Matem., v.10, n.3, p.79-92, 2019. doi: 10.26843/ rencima.v10i3.2123

CURY, C. R. J. Livro didático como assistência ao estudante. Rev. Diálogo Educ., v.9, n.26, p.119-130, 2009.

DARIDO, S.C. et al. Práticas corporais: Educação Física. São Paulo: Moderna. 2018.

DEON, A.R.; CALLAI, H.C. Educação escolar e formação cidadã: possibilidades de análise a partir de livro didático de Geografia. Rev. Bras. Educ. Geografia, v.8, n.15, p.39-62, 2018.

FNDE. Fundo Nacional de Desenvolvimento da Educação, 2017. Dados estatísticos sobre o PNLD. 2018. Disponivel em: $<$ https:// www.fnde.gov.br/index.php/programas/programas-do-livro/ pnld/dados-estatisticos $>$. Acesso em: 1 fev.2020.

FREITAS, L.M.A.; VAZQUEZ, R.P. Língua Estrangeira e Língua Portuguesa no edital do PNLD 2011: aproximações e distanciamentos. Rev. Práticas Educ. Bás., v.2, n.2, p.1-26, 2017.

FREITAS, N.K.; RODRIGUES, M.H. O livro didático ao longo do tempo: a forma do conteúdo. DAPesquisa, v.3, n.5, p.300-307, 2019.

GONÇALVES, R.C.; GERMINARI, G.D. Livro didático do PNLD campo: considerações sobre ensino de História em escolas localizadas no campo. Hist. Ensino, v.25, n.1, p.97-118, 2019. doi: http://dx.doi.org/10.5433/22383018.2019v25n1p97

GUIMARÃES, A.A. et al. Educação Física escolar: atitudes e valores. Motriz, v.7, n.1, p.17-22, 2001.

KATUTA, Â.M.; DÉAK, S.C.P. O livro didático de geografia para as séries inicias do Ensino Fundamental e formação docente no Brasil. Terra Livre, v.1, n.44, p.114-143, 2017.

MACIEL, G.N. O Programa Nacional do Livro Didático e as mudanças nos processos de avaliação dos livros de geografia. Rev. Estud. Pesq. Ensino Geog., v.1, n.1, p.231-253, 2014.

MAGALHÃES, J.S.; KOBAL, M.C.; GODOY, R.P. Educação física na educação infantil: uma parceria necessária. Rev. Mackenzie Educ. Fís. Esporte, v.6, n.3, p.43-52, 2007.

MANCINI, M.C.; SAMPAIO, R.F. Quando o objeto de estudo é a literatura: estudos de revisão. Braz. J. Phys. Ther., v.10, n.4, 2006.

MIRANDA, S.R.; LUCA, T.R. O livro didático de história hoje: um panorama a partir do PNLD. Rev. Bras. Hist., v.24, n.48, p.123-144, 2004.

MOREIRA, D.M.; STRIEDER, D.M. O livro didático e suas relações com a educação alimentar. Rev. Bras. Inic. Cient., v.6, n. 7, p.108-124, 2019.

NOGUEIRA, A.L.H.; SILVA, M.A.; COLOMBO, S.R. O trabalho do professor em propostas do PNLD de ensino de língua portuguesa. Educ. Realidade, v.43, n.1, p.313, 2018.

PEREIRA, R.F.; CONTI, K.C. O tratamento da informação presente em livro didático de matemática do $5^{\circ}$ ano do ensino fundamental. Momentum, v.1, n.9, p.121-134, 2017.

PINA, Fabiana. O acordo MEC-USAID: ações e reações (19661968). Assis: Universidade Estadual Paulista, 2011.

PORTO, A.L.A. Livros didáticos de história: uma história comparada de Brasil e Cuba (2013-2015). São Cristóvão: Universidade Federal de Sergipe, 2019.

QUEIROZ JUNIOR, E.C.; ROCHA, F.R.L. Revistando o livro de história do $1^{\circ}$ ano da educação básica através da lei 10.639/2003. Rev. Favor Igualdade Racial, v.2.1, p.58-70, 2019.

RIBEIRO, D.M.; PAULINO, M.F.R.S.; CARVALHO, S.M. Análise do ensino da produção escrita do artigo de opinião no livro didático de língua portuguesa $9^{\circ}$ ano. Web Rev. Ling. Educ. Memória, v.8, n.8, p.1-14, 2015.

RIBEIRO, M.; AMARAL, R. Guia e tecnologia dos/nos livros didáticos de matemática: uma primeira discussão. Educ. Matem. Rev., p.64-75, 2016.

ROMANO, G.; SCHIMIGUEL, J.; FERNANDES, M.E. Uma revisão bibliográfica e pesquisa sobre livros didáticos de matemática, tecnologia e ensino de geometria no ensino fundamental e médio. Rev. Ensino Ciênc. Matem., v.10, n.4, p.212-226, 2019.

SANTOS, L.A.; LUIZ, E.L. Ensino dos conteúdos sobre relevo na Geografia Escolar: análise de uma coleção de livros didáticos dos anos finais do ensino fundamental. Geografia, v.28.2, p.233248, 2019.

SANTOS, N.Q.; SCHNNIEDER, E.M.; DELLA JUSTINA, L.A. Obstáculos epistemológicos sobre a água em livros didáticos de ciências do sexto ano do ensino fundamental, no PNLD 2017 do Brasil. Góndola, Enseñanza Aprendizaje Cienc., v.14, n.2, p. 376391, 2019.

SILVA, A. B. Um estudo da representação de triângulos em livros didáticos da alfabetização matemática. Rev. Paran. Educ. Matem., v.4, n.6, p.158-176, 2015.

SILVA, F.A.; ALVES, J.Q.; ANDRADE, J.J. O livro didático como documento histórico para análise do currículo de Química e Ciências. Rev. Triângulo, v.12, n.1, p.43-67, 2019.

SILVA, M.A. A fetichização do livro didático no Brasil. Educ. Realidade, v.37, n.3, p.803-821, 2012.

SOARES, F.; ROCHA, J.L. As políticas de avaliação do livro didático na Era Vargas: a Comissão Nacional do Livro Didático. Zetetike, v.13, n.2, p.81-112, 2005.

SOUZA, L.H.P. As imagens dos livros didáticos de ciências para os anos iniciais do ensino fundamental e as visões de saúde que 
SILVA, I.A.; PAULA, C.F.C.; FERNANDES, I.P.L.; OLIVEIRA, N.C.R.; ANACLETO, F.N.A.

veiculam. Rev. Horizontes, v.37, n.1, p.1-18, 2019.

STALLIVIERI, R.; BERTON, D. Manual do professor para a Educação Física. Curitiba: Terra Sul, 2018.

STURION, B.C.; AMARAL-SCHIO, R.B. BNCC do Ensino
Médio: um olhar sobre os conteúdos de área e volume nos livros didáticos de Matemática. Tangram, v.2, n.3, p.88-102, 2019.

TAMANINI, P.A.; NORONHA, V.M.G. O ensino de história e a BNCC: livros didáticos sob uma análise comparativa. Rev. Teias, v.20, p.109-124, 2019. 